Eike S. Dettmann

Thomas F. Lüscher

Josef Flammer

Ivan O. Haefliger

\section{Modulation of endothelin-1-induced contractions by magnesium/calcium in porcine ciliary arteries}

Received: 10 January 1997

Revised version received: 2 April 1997

Accepted:8 April 1997
Presented in part as a poster at the 5th Congress of the European Glaucoma Society, Paris, France, 19-22 June 1996

E.S. Dettmann - J. Flammer

I.O. Haefliger (ख)

Laboratory of Ocular Pharmacology and Physiology,

University Eye Hospital Basel,

Mittlere Strasse 91, P.O.

CH-4012 Basel, Switzerland

Tel. +41-61-265-8787;

fax: $+41-61-265-8652$

T.F. Lüscher

Cardiology, University Hospital Zürich,

Switzerland

\begin{abstract}
Background: The present study was performed to investigate the influence of extracellular magnesium on changes in contractile tone induced by endothelin- 1 , and on relaxations to bradykinin in isolated porcine ciliary arteries. - Methods: Vessels were studied in a myograph system for measurement of isometric forces.Concentrationresponse curves $\left(10^{-10}-10^{-7} \mathrm{M}\right)$ to endothelin-1 were constructed in the presence of different concentrations $(0,1.2,2,10 \mathrm{mM})$ of magnesium $\left(\mathrm{MgSO}_{4}\right)$. Endothelin-1-precontracted vessels $\left(\sim 10^{-8} \mathrm{M}\right)$ were exposed to magnesium $\left(10^{-5}-10^{-2} \mathrm{M}\right)$ in the presence or absence of either the inhibitor of nitric oxide formation L-NAME $\left(\sim 10^{-4} \mathrm{M}\right)$, or different concentrations of calcium $(2.5,5$, $10 \mathrm{mM}$ ). In endothelin-1-precontracted vessels $\left(10^{-8} \mathrm{M}\right)$, relaxations to bradykinin $\left(10^{-10}-10^{-6} \mathrm{M}\right)$ were
\end{abstract}

conducted in the presence of different concentrations of magnesium $(0,1.2$, $10 \mathrm{mM}$ ). Results: Contractions to endothelin-1 were reduced only in the presence of $10 \mathrm{mM}$ magnesium. (1.2 $\mathrm{mM}$ vs $10 \mathrm{mM}, P=0.001$ ). In endothelin-1-precontracted vessels, magnesium evoked complete concentration-dependent relaxations $\left(\mathrm{pD}_{2}=3.1 \pm 0.1\right)$, which were shifted to the right by increasing extracellular concentrations of calcium ( $2.5 \mathrm{vs}$ $5 \mathrm{mM}, P<0.05)$. L-NAME had no influence on magnesium-induced relaxations. Relaxations to bradykinin remained unaffected by changes in extracellular magnesium concentrations. Conclusions: In a mechanism which appears to be compatible with a calcium-antagonist effect, magnesium strongly modulates changes in contractile tone evoked by endothelin-1, but has no effect on bradykinin-induced relaxations.

\section{Introduction}

Various endothelial-derived substances modulate vascular tone. Among them are the potent vasoconstrictor, endothelin- 1 , and the vasorelaxing factor, nitric oxide (NO) $[11,12,20,23]$.

Endothelin-1, after binding to specific receptors on vascular smooth muscle cells, activates phospholipase $\mathrm{C}$ and leads - via formation of inositol triphosphate and diacylglycerol - to an increase in intracellular calcium and eventually to a contraction [21, 29]. In some vascular beds, the endothelin-1-induced intracellular calci- um increase has been shown to be, in part, due to an influx of extracellular calcium through voltage-operated channels [10]. As a result, in certain vascular beds, calcium antagonists are effective in inhibiting endothelin-1induced contractions [15]. For example, in the ophthalmic circulation, modulation of endothelin-1-induced contractions by calcium antagonists could be shown $[24,27]$.

NO is formed from L-arginine by a specific NO synthase in endothelial cells under basal conditions or after activation by some agonists, such as bradykinin [20]. In vascular smooth muscle cells, NO stimulates a guanylate cyclase, which in turn increases intracellular cGMP con- 
centration and leads, by lowering the intracellular calcium concentration, to a relaxation [28].

Extracellular magnesium concentration modulates vascular contractile tone. In precontracted vessels, magnesium causes vasorelaxations, and contractions to various agonists were attenuated in the presence of high concentrations of magnesium $[1,3,6,18,31,32]$. These effects have usually been attributed to a calcium-antagonist-like mechanism $[13,14,18]$ and it has been suggested that magnesium is able to regulate calcium flux across the vascular smooth muscle cell membranes. It has also been reported that magnesium could interfere with the calcium release from intracellular storage sites, as well as with the basal formation and/or the release of NO $[9,17]$.

This study investigates, in isolated porcine ciliary arteries, the influence of magnesium on contractions to endothelin-1 and on NO-induced endothelium-dependent relaxations evoked by bradykinin [34].

\section{Materials and methods}

Blood-vessel preparation

Porcine eyes were obtained at a slaughterhouse just after death of animals. In cold modified Krebs-Ringer solution $(\mathrm{NaCl} 118 \mathrm{mM}$, $\mathrm{KCl} 4.7 \mathrm{mM}, \mathrm{CaCl}_{2} 2.5 \mathrm{mM}, \mathrm{KH}_{2} \mathrm{PO}_{4} 1.2 \mathrm{mM}, \mathrm{MgSO}_{4} 1.2 \mathrm{mM}$, $\mathrm{NaHCO}_{3} 25 \mathrm{mM}$, glucose $11.1 \mathrm{mM}$ ), ciliary arteries were isolated and cut into 2-mm-long rings [25]. In an organ chamber, two 40$\mu \mathrm{m}$ stainless wires were passed through the vessel's lumen and attached to a force transducer for isometric force measurement and to a micromanipulator (Myo-Interface, JP Trading, Aarhus, Denmark). Vessels were left for $30 \mathrm{~min}$ for equilibration in the modified Krebs-Ringer solution $\left(95 \% \mathrm{O}_{2}, 5 \% \mathrm{CO}_{2}, 37{ }^{\circ} \mathrm{C}\right.$, and indomethacin $10^{-5} \mathrm{M}$ to block prostaglandin synthesis). Vessels were then stretched in a stepwise fashion to reach their optimal passive tension (ca. $950 \mathrm{mg}$ ) [11, 24].Then vessels were exposed several times to $\mathrm{KCl} 100 \mathrm{mM}$ until they showed reproducible contractions (i.e. less than $10 \%$ variation between two successive $\mathrm{KCl}$-induced contractions). The endothelial function was considered to be intact if bradykinin $\left(10^{-8}-10^{-6} \mathrm{M}\right)$ evoked more than $80 \%$ relaxation of a vessel precontracted with the thromboxane $A_{2}$ analog $U 46619\left(10^{-7} \mathrm{M}\right)$.

\section{Experimental protocol}

In the presence of different concentrations of magnesium $(0,1.2,2$, and $10 \mathrm{mM})$, concentration-response curves to ET $-1\left(10^{-10}-10^{-7} \mathrm{M}\right)$ were constructed. Isotonicity was maintained by adjusting the $\mathrm{NaCl}$ concentration. In another set of experiments endothelin-1-precontracted vessels $\left(\sim 10^{-8} \mathrm{M}\right)$ were exposed to increasing concentrations of $\mathrm{MgCl}_{2}$ and/or $\mathrm{MgSO}_{4}\left(10^{-5}-10^{-2} \mathrm{M}\right):$ (a) in the presence or absence of the inhibitor of nitric oxide formation $N^{\mathrm{G}}$-nitro-L-arginine methyl ester (L-NAME; $10^{-4} \mathrm{M}$ ), and (b) in the presence of different concentrations of $\mathrm{Ca}^{2+}(2.5,5$, and $10 \mathrm{mM})$. In all these experiments, the precontraction to endothelin-1 was achieved in a magnesiumfree medium. To rule out an osmolarity effect, a control was conducted with $\mathrm{NaCl}$ (same osmolarity as $\mathrm{MgSO}_{4}$ ). Finally, after precontracting vessels with endothelin-1 $\left(\sim 10^{-8} \mathrm{M}\right)$, a relaxation-response curve to bradykinin $\left(10^{-10}-10^{-6} \mathrm{M}\right)$ was constructed in the presence of different concentrations of magnesium $(0,1.2$, and $10 \mathrm{mM}$ ). It has to be mentioned that concentrations of ET-1 were adapted $\left(10^{-8} \mathrm{M}\right.$ to $\left.3 \times 10^{-8} \mathrm{M}\right)$ in order to reach equivalent levels of precontraction.
Drugs

Bradykinin, L-NAME, indomethacin, and U46619 were obtained from Sigma Chemical (St. Louis, Mo.), and endothelin-1 from Novabiochem (Läufigen, Switzerland). All drugs were dissolved in distilled water except U46619 and indomethacin, which were dissolved in $10^{-5} \mathrm{M} \mathrm{Na}_{2} \mathrm{CO}_{3}$, and endothelin-1, which was dissolved in Krebs solution containing $0.05 \%$ bovine serum albumin. Concentrations were expressed as final molar concentrations in the organ chamber.

Statistical analysis

Contractions were expressed as percentage of contraction to $100 \mathrm{mM}$ $\mathrm{KCl}$ and relaxations as percentage of the precontraction to endothelin- $1\left(10^{-8} \mathrm{M}\right)$. The concentration causing $50 \%$ of the maximal response ( $\mathrm{EC}_{50}$ value) was expressed as a negative $\log \mathrm{M}$ concentration ( $\mathrm{pD}_{2}$ value). Results are given as mean \pm standard error of the mean (mean \pm SEM), and $n$ equals the number of eyes (one eye per animal). For statistical comparison analysis of variance (ANOVA; Scheffe's F test) was used. A two-tailed $P$ value smaller than 0.05 was considered to be statistically significant.

\section{Results}

Magnesium modulates endothelin-1-induced contractions

In porcine ciliary arteries, endothelin-1-induced, under control conditions $\left(\mathrm{Mg}^{2+} 1.2 \mathrm{mM}\right)$, potent concentrationdependent contractions, with a maximal effect of $111 \pm 4 \%$ of $\mathrm{KCl} 100 \mathrm{mM}$ contraction and $\mathrm{a}_{2}$ value of $7.9 \pm 0.1$ (Fig. 1). Responses were not significantly affected by decreasing magnesium concentrations to $0 \mathrm{mM}$ or increasing to $2 \mathrm{mM}$. Only at a concentration of $10 \mathrm{mM}$ could a significant reduction of the maximal contractile

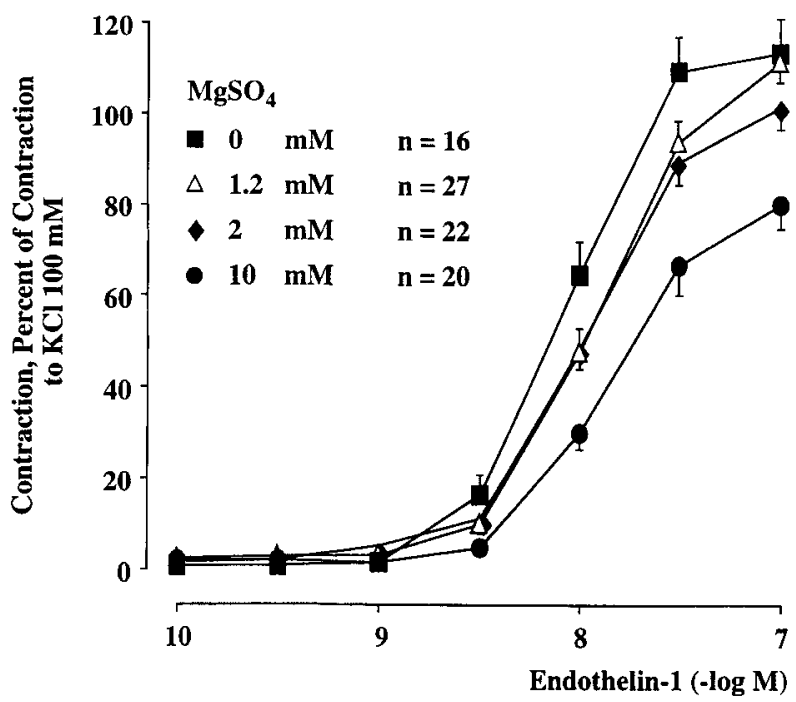

Fig. 1 Effect of different extracellular $\mathrm{MgSO}_{4}$ concentrations on endothelin-1-induced contractions. In comparison to control conditions $(1.2 \mathrm{mM})$, only at a concentration of $10 \mathrm{mM}$ could a significant reduction of the maximal contractile effect of endothelin- 1 be observed $(P=0.001)$ 


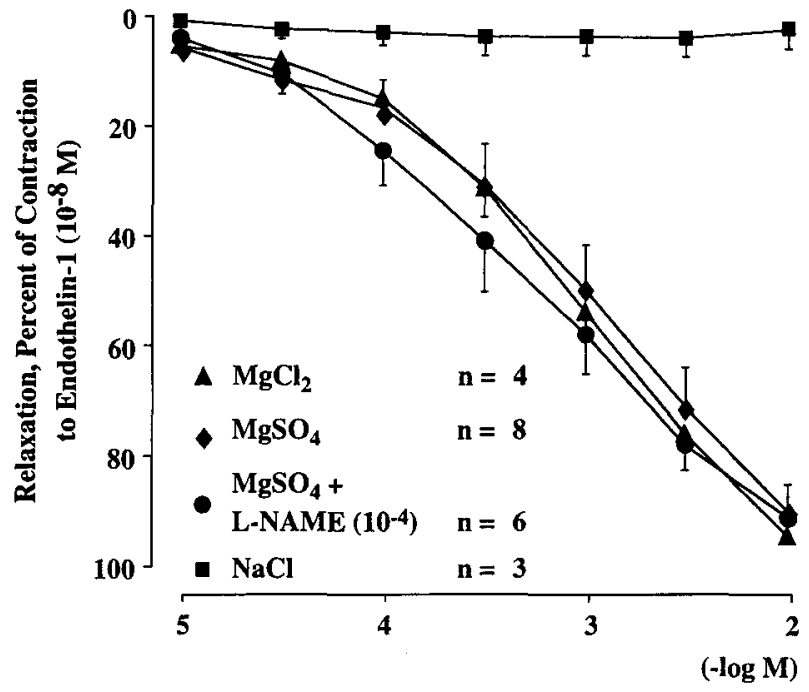

Fig. 2 Similar relaxing effect of increasing concentrations of $\mathrm{MgSO}_{4}$ and $\mathrm{MgCl}_{2}$ added to endothelin-1-precontracted porcine ciliary arteries $\left(\sim 10^{-8} \mathrm{M}\right)$. $\mathrm{NaCl}$, which has the same osmolarity as $\mathrm{MgSO}_{4}$, did not evoke a relaxation. The relaxation to $\mathrm{MgSO}_{4}$ was unaffected by the inhibitor of nitric oxide formation L-NAME

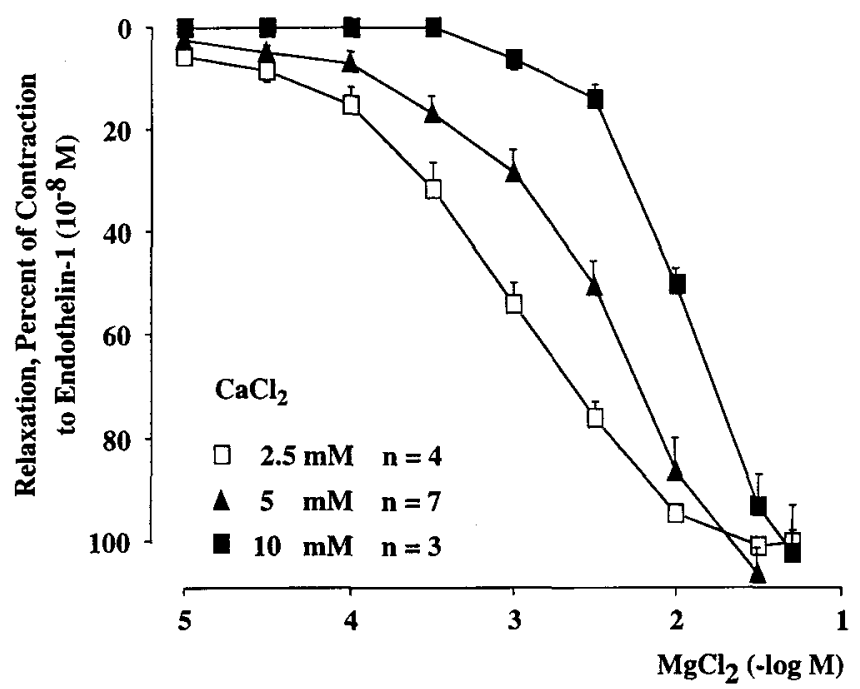

Fig. 3 Effect of different extracellular $\mathrm{CaCl}_{2}$ concentrations on $\mathrm{MgCl}_{2}$-induced relaxations. The relaxation-response curves to magnesium were significantly shifted to the right in presence of increasing concentrations of calcium $(2.5$ vs $5 \mathrm{mM}: P<0.01 ; 5$ vs $10 \mathrm{mM}$ : $P<0.05)$

effect of endothelin- 1 be observed $\left(E_{\max }=80 \pm 6 \%\right.$, $P=0.001$ vs control).

\section{Magnesium relaxes endothelin-1-precontracted vessels}

In arteries precontracted with endothelin- $1\left(10^{-8} \mathrm{M}\right)$ in magnesium-free medium, both $\mathrm{MgCl}_{2}$ and $\mathrm{MgSO}_{4}\left(10^{-5}\right.$

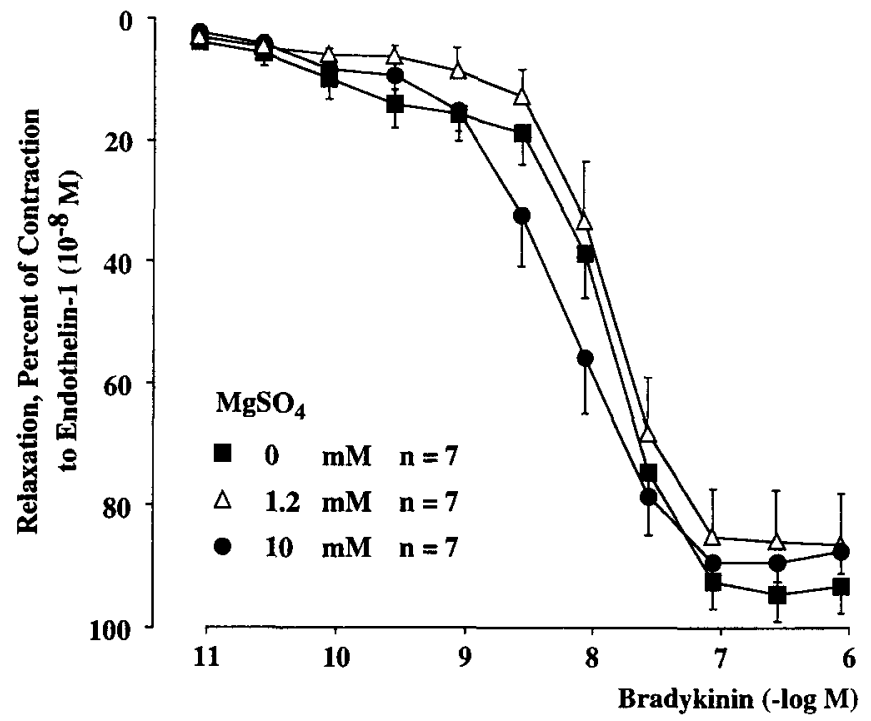

Fig. 4 Effect of different extracellular $\mathrm{MgSO}_{4}$ concentrations on bradykinin-induced relaxations. In comparison to control experiments $(1.2 \mathrm{mM})$, the relaxation-response curve to bradykinin appeared to be unaffected by changes of the extracellular magnesium concentrations

$\left.-10^{-2} \mathrm{M}\right)$ evoked complete concentration-dependent relaxations $\left(\mathrm{MgCl}_{2}: \operatorname{relax}_{\max }=95 \pm 1 \%, \mathrm{pD}_{2}=3.1 \pm 0.1\right)$. The two magnesium salts showed similar concentrationrelaxation curves, whereas $\mathrm{NaCl}$ had no relaxing effect, excluding an unspecific effect of magnesium related to changes in osmolarity. Furthermore, the relaxing effect of $\mathrm{MgSO}_{4}$ was unaffected by the inhibitor of NO formation, L-NAME $\left(10^{-4} \mathrm{M}\right)$, demonstrating that in porcine ciliary arteries NO is not involved in the relaxation evoked by magnesium (Fig. 2).

Extracellular calcium concentration modulates relaxations to magnesium

In vessels precontracted with endothelin- $1\left(\sim 10^{-8} \mathrm{M}\right)$ in magnesium-free medium, changes of the calcium concentration $(2.5,5$, and $10 \mathrm{mM})$ in the medium affected the relaxation to $\mathrm{MgCl}_{2}$. Increasing extracellular calcium concentrations resulted in a rightward shift of the concentration-response curve $\left(2.5\right.$ vs $5 \mathrm{mM}: \mathrm{pD}_{2}=3.1 \pm 0.1$ vs $\mathrm{pD}_{2}=2.5 \pm 0.1, P<0.01 ; 5$ vs $10 \mathrm{mM}: \mathrm{pD}_{2}=2.5 \pm 0.1$ vs $\mathrm{pD}_{2}=2.0 \pm 0.0, P<0.05$ ) without affecting the $\max$ imal relaxing effect of magnesium (Fig. 3).

Magnesium- and bradykinin-induced relaxations

In porcine ciliary arteries precontracted with endothelin-1 $\left(\sim 10^{-8} \mathrm{M}\right)$, bradykinin $\left(10^{-11}-10^{-6} \mathrm{M}\right)$ evoked concentration-dependent relaxations. In comparison to control ex- 
periments the relaxation-response curve to bradykinin was not affected by changes in extracellular magnesium concentrations, demonstrating that in porcine ciliary arteries bradykinin-induced relaxations remain unaffected by changes of the extracellular magnesium concentration (Fig. 4).

\section{Discussion}

The present study demonstrates that in porcine ciliary arteries, extracellular magnesium concentrations modulate changes in contractile tone induced by endothelin- 1 . The potent contracting effect of endothelin-1 was blunted by elevated extracellular concentrations of magnesium, while in endothelin-1-precontracted vessels magnesium evoked potent and complete relaxations in a concentration-dependent manner. The magnesium-induced relaxations were shifted to the right by increasing the extracellular concentration of calcium. Finally, relaxations to bradykinin remained unaffected by changes in extracellular concentrations of magnesium.

Magnesium has been shown to have calcium-antagonist-like properties $[13,14]$ and to inhibit calcium influx through voltage-operated calcium channels $[18,31]$. In certain vascular beds calcium antagonists partially attenuate the contraction to endothelin-1 [15], while they are more potent in reversing an endothelin-1-induced precontraction [33]. Therefore it has been suggested that in these vascular beds the development of endothelin-1-induced contractions is essentially dependent of the release of calcium from intracellular storage sites, while the maintenance of the contraction could involve voltage-operated calcium channels [33]. In a similar way, the present study shows that magnesium is less efficient in preventing the development of a contraction to endothelin-1 (when added before the contraction) than in reversing a contraction to endothelin-1 (when added once the contraction is fully developed). Indeed, in the presence of $10 \mathrm{mM}$ of magnesium, the contraction to $10^{-8} \mathrm{M}$ endothelin-1 was only partially inhibited (Fig. 1), while once the contraction to $10^{-8} \mathrm{M}$ endothelin- 1 was fully developed, addition of $10 \mathrm{mM}$ of magnesium evoked a complete relaxation of the vessels (Fig. 2). A similar phenomenon has already been reported in goat cerebral arteries [32], where magnesium reversed an endothelin-1-induced contraction, even though it had no significant effect when added before the contraction to endothelin-1.

The range of normal magnesium concentration in the plasma of healthy subjects ranges between 0.7 and $1.1 \mathrm{mmol} / 1$. At concentrations as high as $1.5 \mathrm{mM}$ first hemodynamic symptoms such as systemic hypotension and tachycardia can be observed. With higher concentrations $(>7.5 \mathrm{mM})$ cardiac arrest can be induced [5]. The results of this in vitro pharmacological study clearly show that already at physiological magnesium concentrations
$(1.0 \mathrm{mM})$, about $50 \%$ relaxation can be observed in vessels precontracted with endothelin- 1 in magnesium-free medium, while to blunt the development of a contraction evoked by endothelin-1 nonphysiological concentrations of magnesium are needed.

Endothelin-1-precontracted vessels were fully and concentration-dependently relaxed by $\mathrm{MgSO}_{4}$ and $\mathrm{MgCl}_{2}$, whereas in comparison $\mathrm{NaCl}$ had no relaxing effect, ruling out an unspecific osmolarity effect of $\mathrm{MgSO}_{4}$ and thereby demonstrating that the observed relaxing effect was indeed due to magnesium (Fig. 2). With increasing concentrations of calcium, the relaxation-response curve to magnesium was shifted to the right, demonstrating that the sensitivity to magnesium is closely related to the extracellular calcium concentration (Fig. 3). This corroborates studies in which it has been suggested that magnesium is able to regulate calcium flux across the vascular smooth muscle cell membranes [3, 18, 30, 31]. Furthermore, this observation underlines the importance of the calcium/magnesium concentration ratio in the maintenance of contractions evoked by endothelin-1. Although the exact mechanism of magnesium-induced relaxations in porcine ciliary arteries remains to be further investigated, magnesium appears to have some calcium-antagonistic properties.

The mechanism of the effect of magnesium on vascular tone is still debated, and in some vascular beds NO has been shown to be involved in the relaxing effect of magnesium [19]. In porcine ciliary arteries L-NAME, an inhibitor of NO formation, did not affect the magnesium-induced relaxation, demonstrating that in these vessels the relaxing effect of magnesium does not involve NO. This is in agreement with some reports showing an endothelium independency of the relaxations to magnesium [2].

In porcine ciliary arteries relaxations to bradykinin were unaffected by magnesium (Fig. 4), demonstrating that the NO production and action evoked by bradykinin is unaffected by changes in the extracellular magnesium concentration. This corroborates the lack of effect of calcium antagonists on bradykinin-induced relaxations in porcine ciliary arteries [24].

In conclusion, magnesium, which appears to share some common features with calcium antagonists, is a potent modulator of endothelin-1-induced contractions in porcine ciliary arteries. As calcium antagonists have been proposed for the treatment of some ocular vascular diseases $[8,16,26]$, magnesium, due to its calcium antagonist properties, could be considered as a potential alternative [7]. Such an approach has already been proposed for the treatment of several vascular diseases, such as migraine $[4,22]$.

Acknowledgements The authors thank Dr. H.P. Gurdan, F. Litzler and F. German for technical help at the slaughterhouse (Basel, Switzerland). This work was supported by the Swiss National Research Foundation (grant 32-42564.94), the Schwickert Foundation, and the Velux Foundation. 


\section{References}

1. Alborch E, Salom JB, Perales AJ, Torregrosa G, Miranda FJ, Alabadi JA, Jover $T$ (1992) Comparison of the anticonstrictor action of dihydropyridines (nimodipine and nicardipine) and $\mathrm{Mg}^{2+}$ in isolated human cerebral arteries. Eur $\mathbf{J}$ Pharmacol 229: 83-89

2. Aloamaka CP, Ezimokhai M, Morrison J, Cherian T (1993) Effect of pregnancy on relaxation of rat aorta to magnesium. Cardiovasc Res 27: 1629-1633

3. Altura BM, Altura BT (1981) Magnesium ions and contraction of vascular smooth muscle: relationship to some vascular diseases. Fed Proc 40: 26722679

4. Castelli S, Meossi C, Domenici R, Fontana F, Stefani G (1993) Magnesium in the prophylaxis of primary headache and other periodic disorders in children. Pediatr Med Chir 15: 481-488

5. Durlach J (1992) Magnesium Überschuss. In: Durlach J (ed) Magnesium in der klinischen Praxis. Fischer, Jena, pp 216-231

6. Farago M, Szabo C, Dora E, Horvath I, Kovach AGB (1991) Contractile and endothelium-dependent dilatory responses of cerebral arteries at various extracellular magnesium concentrations. J Cereb Blood Flow Metab 11: 161-164

7. Gaspar AZ, Gasser P, Flammer J (1995) The influence of magnesium on visual field and peripheral vasospasm in glaucoma. Ophthalmologica 209: 11-13

8. Gasser P, Flammer J (1990) Short- and long-term effect of nifedipine on the visual field in patients with presumed vasospasm. J Int Med Res 18: 334-339

9. Gold ME, Buga GM, Wood KS, Byrns RE, Chaudhuri G, Ignarro LJ (1990) Antagonistic modulatory roles of magnesium and calcium on release of endothelium-derived relaxing factor and smooth muscle tone. Circ Res 66: 355366

10. Goto K, Kasuya Y, Matsuki N, Takuwa Y, Kurihara H, Ishikawa T, Kimura S, Yanagisawa M, Masaki T (1989) Endothelin activates the dihydropyridinesensitive, voltage-dependent $\mathrm{Ca}^{2+}$ channel in vascular smooth muscle. Proc Natl Acad Sci USA 86: 3915-3918

11. Haefliger IO, Flammer J, Lüscher TF (1992) Nitric oxide and endothelin-1 are important regulators of human ophthalmic artery. Invest Ophthalmol Vis Sci 33: $2340-2343$
12. Haefliger IO, Flammer J, Lüscher TF (1993) Heterogeneity of endotheliumdependent regulation in ophthalmic and ciliary arteries. Invest Ophthalmol Vis Sci 34: $1722-1730$

13. Iseri LT, French JH (1984) Magnesium: nature's physiologic calcium blocker. Am Heart J 108: 188-194

14. Karaki H, Hatano K, Weiss GB (1983) Effects of magnesium on ${ }^{45} \mathrm{Ca}$ uptake and release at different sites in rabbit aortic smooth muscle. Pflugers Arch 398: 27-32

15. Kiowski W, Lüscher TF, Linder L, Bühler FR (1991) Endothelin-1-induced vasoconstriction in humans: reversal by calcium channel blockade but not by nitrovasodilators or endothelium derived relaxing factor. Circulation 83: 469-475

16. Kitazawa Y, Shirai H, Go FJ (1989) The effect of calcium-antagonists on visual field in low-tension glaucoma. Graefe's Arch Clin Exp Ophthalmol 227: 408412

17. Ku DD, Ann SH (1991) Differential effects of magnesium on basal and agonist-induced EDRF relaxation in canine coronary arteries. J Cardiovasc Pharmacol 17: 999-1006

18. Kumasaka D, Lindeman KS, Clancy J, Lande B, Croxton TL, Hirshman CA (1996) $\mathrm{MgSO}_{4}$ relaxes porcine airway smooth muscle by reducing $\mathrm{Ca}^{2+}$ entry. Am J Physiol 270: L469-74

19. Laurant $P$, Berthelot A (1994) Influence of endothelium on $\mathrm{Mg}^{2+}$-induced relaxation in noradrenaline-contracted aorta from DOCA-salt hypertensive rat. Eur J Pharmacol 258: 167-172

20. Lüscher TF (1990) In: Lüscher TF, Vanhoutte PM (eds) The endothelium: modulator of cardiovascular function. CRC Press, Boca Raton, pp 1-228

21. Marsden PA, Danthuluri NR, Brenner BM, Ballermann, BJ Brock TA (1989) Endothelin action on vascular smooth muscle involves inositol triphosphate and calcium mobilization. Biochem Biophys Res Commun 158: 86-93

22. Mauskop A, Altura BT, Cracco RQ, Altura BT (1995) Intravenous magnesium sulphate relieves migraine attacks in patients with low serum ionized magnesium levels: a pilot study. Clin Sci Colch 89: 633-636

23. Meyer P, Flammer J, Lüscher TF (1993) Endothelium-dependent regulation of the ophthalmic microcirculation in the perfused porcine eye: role of nitric oxide and endothelins. Invest Ophthalmol Vis Sci 34: 3614-3621
24. Meyer P, Lang MG, Flammer J, Lüscher TF (1995) Effects of calcium channel blockers on the response to endothelin1, bradykinin and sodium nitroprusside in porcine ciliary arteries. Exp Eye Res 60: $505-510$

25. Mulvani MJ, Halpern W (1976) Mechanical properties of vascular smooth muscle in situ. Nature 260: 617

26. Netland PA, Chaturvedi N, Dreyer EB (1993) Calcium channel blockers in the management of low-tension and openangle glaucoma. Am J Ophthalmol 115: $608-613$

27. Nyborg NC, Prieto D, Benedito S, Nielsen PJ (1991) Endothelin-1-induced contraction of bovine retinal small arteries is reversible and abolished by nitrendipine. Invest Ophthalmol Vis Sci 32: 27-31

28. Palmer RMJ, Ashton DS, Moncada S (1988) Vascular endothelial cells synthesize nitric oxide from L-arginine. Nature 333: 664-666

29. Resink TJ, Scott-Burden T, Bühler FR (1988) Endothelin stimulates phospholipase $\mathrm{C}$ in cultured vascular smooth muscle cells. Biochem Biophys Res Commun 157: 1360-1368

30. Skajaa K, Forman A, Andersson KE (1990) Effects of magnesium on isolated human fetal and maternal uteroplacental vessels. Acta Physiol Scand 139: 551559

31. Skajaa K, Svane D, Andersson KE, Forman A (1990) Effects of magnesium and isradipine on contractile activation induced by the thromobxane $\mathrm{A}_{2}$ analog U46619 in human utero-placental arteries in term pregnancy. Am J Obstet Gynecol 163: 1323-1333

32. Torregrosa G, Pearles AJ, Salom JB, Miranda FJ, Barbera MD, Alborch E (1994) Different effects of $\mathrm{Mg}^{2+}$ on endothelin-1- and 5-hydroxytryptamineelicited response in goat cerebrovascular bed. J Cardiovasc Pharmacol 23: 1004 1010

33. Yang Z, Bauer E, Von Segesser L, Stulz P, Turina M, Lüscher TF (1990) Different mobilization of calcium in endothelin-1-induced contractions in human arteries and veins: effects of calcium antagonists. J Cardiovasc Pharmacol 16: 654-660

34. Zhu P, Bény JL, Flammer J, Lüscher TF, Haefliger IO (1997) Relaxation by bradykinin in porcine ciliary artery: role of nitric oxide and $\mathrm{K}^{+}$-channels. Invest Ophthalmol Vis Sci 38: 1761-1767 